\title{
Protective effect of fruits, vegetables and the Mediterranean diet on asthma and allergies among children in Crete
}

\author{
Leda Chatzi, Gianna Apostolaki, loannis Bibakis, Isabel Skypala, Vasilki Bibaki-Liakou, Nikolaos \\ Tzanakis, Manolis Kogevinas, Paul Cullinan
}

Thorax 2007;62:677-683. doi: 10.1136/thx.2006.069419

See end of article for authors' affiliations

Correspondence to: Dr P Cullinan, Department of Occupational and Environmental Medicine, Royal Brompton Hospital and National Heart and Lung Institute, London SW3 6LR, UK; p.cullinan@ imperial.ac.uk

Received 29 July 2006 Accepted 11 January 2007 Published Online First

5 April 2007

\begin{abstract}
Background: Atopy is not uncommon among children living in rural Crete, but wheeze and rhinitis are rare. A study was undertaken to examine whether this discrepancy could be attributed to a high consumption of fresh fruit and vegetables or adherence to a traditional Mediterranean diet.

Methods: A cross-sectional survey was performed in 690 children aged 7-18 years in rural Crete. Parents completed a questionnaire on their child's respiratory and allergic symptoms and a 58 -item food frequency questionnaire. Adherence to a Mediterranean diet was measured using a scale with 12 dietary items. Children underwent skin prick tests with 10 common aeroallergens.

Results: $80 \%$ of children ate fresh fruit (and $68 \%$ vegetables) at least twice a day. The intake of grapes, oranges, apples, and fresh tomatoes - the main local products in Crete-had no association with atopy but was protective for wheezing and rhinitis. A high consumption of nuts was found to be inversely associated with wheezing (OR $0.46 ; 95 \% \mathrm{Cl} 0.20$ to 0.98 ), whereas margarine increased the risk of both wheeze (OR $2.19 ; 95 \% \mathrm{Cl} 1.01$ to 4.82 ) and allergic rhinitis (OR 2.10;95\% Cl 1.31 to 3.37). A high level of adherence to the Mediterranean diet was protective for allergic rhinitis (OR $0.34 ; 95 \% \mathrm{Cl} 0.18$ to 0.64 ) while a more modest protection was observed for wheezing and atopy.

Conclusion: The results of this study suggest a beneficial effect of commonly consumed fruits, vegetables and nuts, and of a high adherence to a traditional Mediterranean diet during childhood on symptoms of asthma and rhinitis. Diet may explain the relative lack of allergic symptoms in this population.
\end{abstract}

$\mathrm{T}$ here has been increasing interest in the role of nutrition in the development of asthma, and in the modulating effect of nutrition on environmental exposures. The growth of airways during childhood may be vulnerable to oxidative exposures; suboptimal antioxidant status during this critical period might result in oxidative airway damage, reductions in airway compliance, or both. ${ }^{1}$ Suboptimal dietary intake of antioxidant vitamins, especially vitamins $\mathrm{A}, \mathrm{C}$, and $\mathrm{E}$ and the carotenoids, as well as other antioxidants such as selenium and flavonoids may have an adverse effect on the modulation of oxidative lung stimuli; higher intakes may have beneficial associations with asthma, wheezing symptoms and ventilatory function. ${ }^{1-3}$

Fruits and vegetables contain many potentially important antioxidants that cannot easily be quantified. Several epidemiological studies of adults have demonstrated a reduced risk of asthma in relation to a high fruit intake, ${ }^{4-7}$ but fewer have focused on childhood allergic respiratory diseases and their findings have been inconsistent. The SIDRIA cross-sectional study in Italy showed that intakes of cooked vegetables, tomatoes and fruits rich in vitamin $\mathrm{C}$ were protective factors for current wheezing symptoms. ${ }^{89}$ In another cross-sectional study of 2650 school children in England and Wales, fresh fruit consumption was found to be positively associated with ventilatory function (forced expiratory volume in $1 \mathrm{~s}\left(\mathrm{FEV}_{1}\right)$ ), the association being stronger among children with wheezing, although wheezing itself was not related to fresh fruit consumption. ${ }^{10}$ The CESAR cross-sectional study of children in six Central European countries showed that fruit intake was negatively associated with cough-particularly winter coughbut not with wheeze. ${ }^{11}$ Hijazi et al, ${ }^{12}$ in a case-control study of asthma in 12-year-old children, reported an inverse association of dietary intake of vitamin E with asthma, but little or no association with either vitamin $\mathrm{C}$ or vegetable intake.
The traditional Mediterranean diet is characterised by an increased intake of plant foods such as fruits and vegetables, bread and cereals (primarily whole grain), legumes and nuts. Olive oil serves as the principal source of fat. All these are important sources of dietary antioxidants. Apart from the most widely known antioxidants contained in fruits and vegetables, other compounds such as oleuropein, hydroxytyrosol and other polyphenols present in olive oil possess a marked antioxidant activity and other advantageous biological properties. ${ }^{13}{ }^{14}$ There has to date been no study on the association of adherence to a Mediterranean dietary pattern and the occurrence of asthma and atopy.

Crete is an eastern Mediterranean island where the inhabitants are reputed to have a prototypic Mediterranean diet, although recent changes in lifestyle have modified dietary habits in the population. In a cross-sectional study of children living in rural settings on the island, we found an "intermediate" prevalence of atopy but a low prevalence of allergic disease. ${ }^{15}$ To test the hypothesis that dietary intake of fresh fruits and vegetables rich in antioxidants and adherence to the traditional Mediterranean diet prevent the occurrence of respiratory symptoms related to atopy, we examined nutritional information collected in the same cross-sectional survey.

\section{METHODS}

The survey was conducted in 2001 in four rural areas of Crete, Greece. All school children aged between 7 and 18 years were invited to participate in the study $(\mathrm{n}=857) .{ }^{15}$ Permission was obtained from the appropriate ethical committees (Venizelion Hospital in Heraklion, Royal Brompton Hospital in London, Ministry of Education in Greece). All parents gave written informed consent.

Abbreviations: $\mathrm{BMI}$, body mass index; $\mathrm{FEV}_{1}$, forced expiratory volume in $1 \mathrm{~s}$ 
The parents were invited to complete a questionnaire that included questions on the child's respiratory and allergic symptoms (modified ISAAC questionnaire translated into Greek), family history of allergic diseases, birth order and sibling numbers, levels of parental education and occupation. The questions were forward translated from English to Greek and vice versa by two independent translators. Discrepancies were decided by consensus of both translators.

Children were considered to have current allergic rhinitis when they were reported to have had, over the last 12 months, a runny or blocked nose apart from a common cold/flu. Current seasonal rhinitis was defined by these symptoms during the months of March to September, and "allergic rhinitis ever" by the same symptoms at some point in the past. Current wheezing was defined by any report of wheeze in the past 12 months.

Each child was invited to undergo skin prick tests, in accordance with the ISAAC protocol, using a series of 10 common aeroallergens: grass pollen (Mediterranean mix), Parietaria, olive blossom, Dermatophagoides pteronyssinus, Dermatophagoides farinae, Cladosporium, cat, goat, cockroach and poultry epithelium, all purchased from ALK Abello (Hungerford, UK). Histamine and saline solutions were used as positive and negative controls, respectively. A positive skin prick test was one where the mean weal diameter was at least $3 \mathrm{~mm}$ greater than the response to the negative control. A child was considered atopic if he or she demonstrated a positive reaction to one or more of the 10 allergens.

\section{Assessment of diet}

We measured dietary habits using a detailed food frequency questionnaire. A total of 58 food items were investigated to study nine food categories: vegetables, fruits, nuts, fish, cereal, dairy products, meat, poultry and vegetable fats (margarine). The questionnaire assessed usual weekly food consumption during the previous 12 months with a six-level scale: never, less than once a week, 1-2 times per week, 3-4 times per week, once per day, more than once per day. The degree of adherence to a traditional Mediterranean diet was based on the KIDMED index. ${ }^{16}{ }^{17}$ We made minor adaptations to the index to adapt it for our study population; thus, we excluded the items on consumption of fast foods, sweets, and legumes since this information was not requested in the diet questionnaire used in the study. Weekly consumption of dietary compounds positively associated with the Mediterranean diet was assigned a value of +1 , whereas weekly consumption of compounds with a negative association was assigned a value of -1 . Weekly consumption of more red than white meat was considered a detrimental component and assigned a value of -1 . The original KIDMED index ranged from 0 to 12 and the sums of the values were classified into three levels: $(1) \geqslant 8$, optimal Mediterranean diet; (2) 4-7, improvement needed to adjust intake to Mediterranean patterns; $(3) \leqslant 3$, very low diet quality. ${ }^{16}$ In the present study the index ranged from 0 to 10 and was categorised into three levels: $(1) \geqslant 6$, optimal Mediterranean diet; (2) 4-5, medium quality Mediterranean diet; $(3) \leqslant 3$, low quality Mediterranean diet. In order to compare the results from the use of the KIDMED index with another index evaluating adherence to a Mediterranean diet, we used a second scale based on the "Mediterranean Diet Score" applied to a large cohort study (EPIC) in adults. ${ }^{18}$ Because the index had been developed for adults and our study population involved children, we presumed diary products to be protective and not detrimental dietary compounds and did not include alcohol consumption in the index.

\section{Statistical analysis}

Data analysis was performed using SPSS 13.0 (SPSS Inc, Chicago, Illinois, USA). Univariate analyses of categorical variables were made using Pearson's $\chi^{2}$ test. The outcome variables that were evaluated in relation to diet were: wheezing ever, wheezing ever with atopy, current wheezing, nocturnal dry cough in the last 12 months apart from a common cold/flu, allergic rhinitis ever, allergic rhinitis ever with atopy, current allergic rhinitis, current seasonal allergic rhinitis and atopy. Multivariate logistic regression models were performed to examine the association between fruit and vegetable consumption (in three levels, using "never" as reference) and the outcome variables, after adjusting for the following confounders: age (in years; three categories: 7-12, 13-14, 15-18), sex, body mass index (BMI, age- and sex-adjusted cut off points for normal, overweight, obese children), ${ }^{19}$ parental asthma (yes, no) and number of older siblings (0, 1, 2, 3+). Logistic regression was performed to examine the association between the outcome variables and the consumption of specific nutrients included in the Mediterranean diet index and, separately, with the overall adherence to the Mediterranean diet (in three levels, using "low" level as reference). All models were adjusted for the same confounders. ORs and 95\% CIs were computed.

\section{RESULTS}

Seven hundred and ninety-seven children $193.0 \%$ of those eligible) completed the main questionnaire of the study. Of these, 107 individuals for whom information on 46 or more food items on the food frequency questionnaire (equivalent to $80 \%$ of the total items) was missing were excluded. From the remaining children $(n=690,80.5 \%)$, complete information for all the variables included in the Mediterranean diet index was provided by 537 (62.7\%).

Table 1 presents a description of the study population according to dietary fruit intake. Age, sex, BMI, parental education, number of older siblings, reported parental asthma and current parental farming showed no association with daily fruit intake.

Table 2 presents the weekly intakes of eight different fruits and vegetables known to be high sources of dietary antioxidants. There were very high consumptions of locally produced fruits and vegetables such as oranges, grapes, tomatoes and apples. Daily vegetable consumptions were moderate to low.

The prevalence rates for any wheezing and rhinitis symptoms in the past were $16.8 \%$ and $18.7 \%$, respectively. When these symptoms were combined with atopy, the prevalence rates for wheezing and rhinitis were $5.4 \%$ and $6.7 \%$, respectively. The prevalence of atopy was $22.3 \%$. The occurrence rates of current wheezing and nocturnal dry cough (apart from a cold in the last 12 months) were $4.6 \%$ and $10.9 \%$, respectively. Prevalence rates for current allergic rhinitis and current seasonal allergic rhinitis were $13.3 \%$ and $5.1 \%$, respectively.

Tables 3 and 4 show the associations between wheezing and allergic rhinitis, respectively, and the daily intakes of different fruits and vegetables rich in antioxidants after adjusting for potential confounders. Specifically, daily consumption of grapes (OR $0.19 ; 95 \%$ CI 0.09 to $0.42, p=0.001$ ), oranges (OR 0.30; $95 \%$ CI 0.11 to $0.90, \mathrm{p}<0.05$ ), apples (OR $0.14 ; 95 \%$ CI 0.04 to $0.48, \mathrm{p}<0.01$ ), and fresh tomatoes (OR $0.32 ; 95 \%$ CI 0.15 to $0.67, \mathrm{p}<0.01$ ) was found to have a beneficial effect on wheezing ever symptoms. Atopic sensitisation without wheeze was not significantly related to the intake of either fruits or vegetables. Current wheezing was negatively associated with daily consumption of grapes (OR $0.32 ; 95 \%$ CI 0.10 to $0.97, \mathrm{p}<0.05$ ).

Daily intake of grapes was also inversely associated with allergic rhinitis ever (OR 0.31 ; 95\% CI 0.14 to $0.64, \mathrm{p}<0.01$ ), 
Table 1 Demographic characteristics by fruit consumption per day

\begin{tabular}{|c|c|c|c|c|}
\hline \multirow[b]{2}{*}{ Exposure variable } & \multirow[b]{2}{*}{ All } & \multicolumn{2}{|c|}{ Fruit consumption per day } & \multirow[b]{2}{*}{$\mathrm{p}$ Value } \\
\hline & & $\overline{<2}$ & $\geqslant 2$ & \\
\hline $\mathrm{N}$ & 690 & $134(19.4)$ & $556(80.6)$ & \\
\hline \multicolumn{5}{|l|}{ Age group (years) } \\
\hline $7-12$ & $396(57.4)$ & $73(18.4)$ & $323(81.6)$ & 0.479 \\
\hline $13-14$ & $165(23.9)$ & $31(18.8)$ & $134(81.2)$ & \\
\hline $15-18$ & $129(18.7)$ & $30(23.3)$ & 99 (76.7) & \\
\hline \multicolumn{5}{|l|}{ Sex } \\
\hline Male & $331(48.0)$ & 69 (19.2) & $290(80.8)$ & 0.890 \\
\hline Female & $359(52.0)$ & 65 (19.6) & $266(80.4)$ & \\
\hline \multicolumn{5}{|l|}{ Current parental farming } \\
\hline Full time & $301(43.6)$ & $62(20.6)$ & $239(79.4)$ & 0.752 \\
\hline Part time & $297(43.1)$ & $56(18.9)$ & 241 (81.1) & \\
\hline No farming & $92(13.3)$ & $16(17.4)$ & $76(82.6)$ & \\
\hline \multicolumn{5}{|l|}{ Father's education } \\
\hline None & $27(3.9)$ & $7(25.9)$ & 20 (74.1) & 0.366 \\
\hline Primary school & $337(48.8)$ & $71(21.1)$ & $266(78.9)$ & \\
\hline Secondary school & $301(43.6)$ & $50(16.6)$ & 251 (83.4) & \\
\hline University & $25(3.6)$ & $6(24.0)$ & $19(76.0)$ & \\
\hline \multicolumn{5}{|l|}{ Mother's education } \\
\hline None & $29(4.2)$ & $8(27.6)$ & $21(72.4)$ & 0.389 \\
\hline Primary school & $229(33.2)$ & $46(20.1)$ & $183(79.9)$ & \\
\hline Secondary school & $398(57.7)$ & $71(17.8)$ & 327 (82.2) & \\
\hline University & $34(4.9)$ & $9(26.5)$ & $25(73.5)$ & \\
\hline \multicolumn{5}{|l|}{ Parental asthma } \\
\hline Yes & $47(6.8)$ & $9(19.1)$ & $38(80.9)$ & 0.989 \\
\hline \multicolumn{5}{|l|}{$\mathrm{BMl}^{*}$} \\
\hline Normal & $466(67.5)$ & 90 (19.3) & $376(80.7)$ & 0.687 \\
\hline Overweight & $150(21.7)$ & $30(20.0)$ & $120(80.0)$ & \\
\hline Obese & $54(7.8)$ & $13(24.1)$ & $41(75.9)$ & \\
\hline \multicolumn{5}{|l|}{ Number of older siblings } \\
\hline 0 & $276(20.4)$ & $59(21.4)$ & $217(78.6)$ & 0.266 \\
\hline 1 & $211(26.1)$ & $45(21.3)$ & $166(78.7)$ & \\
\hline 2 & $109(21.2)$ & $16(14.7)$ & $93(85.3)$ & \\
\hline$\geqslant 3$ & $94(32.3)$ & 14 (14.9) & $80(85.1)$ & \\
\hline \multicolumn{5}{|l|}{ Symptoms: atopy } \\
\hline Wheezing ever & $116(16.8)$ & $25(21.6)$ & 91 (78.4) & 0.525 \\
\hline Current wheezing & $32(4.6)$ & $9(28.1)$ & 23 (71.9) & 0.202 \\
\hline Allergic rhinitis ever & 129 (18.7) & $34(26.4)$ & 95 (73.6) & 0.029 \\
\hline Current allergic rhinitis & $92(13.3)$ & 17 (18.5) & 75 (81.5) & 0.801 \\
\hline Atopy & $154(22.3)$ & $33(21.4)$ & $121(78.6)$ & 0.501 \\
\hline
\end{tabular}

BMI, body mass index.

*Numbers do not correspond to the total due to missing values.

current allergic rhinitis (OR 0.36 ; $95 \%$ CI 0.16 to $0.81, \mathrm{p}<0.05$ ) and current seasonal allergic rhinitis (OR 0.18 ; $95 \%$ CI 0.06 to $0.54, \mathrm{p}<0.01)$ after adjusting for potential confounders. The associations showed a significant decreasing trend when intake was higher. Allergic rhinitis ever was also negatively associated with daily intake of oranges (OR $0.29 ; 95 \%$ CI 0.11 to 0.80 , $\mathrm{p}<0.05$ ) and kiwi (OR 0.37; 95\% CI 0.16 to $0.86, \mathrm{p}<0.05$ ), whereas intake of other fruits and vegetables was not significantly related to allergic rhinitis.

Complete information for all the variables included in the Mediterranean diet index was available for 537 (67.4\%) children. Table 5 shows the degree of adherence to the diet among these children. A low index was found for $27.9 \%$ of the sample, $43.8 \%$ had intermediate values, and $28.3 \%$ had a high index. There were no significant associations between the levels of the Mediterranean diet index and sex, parental education status, number of siblings, reported parental asthma and current parental farming. A significant decline was noted with age, the children in the 13-14 year age group having the most favourable values (34.9\% with optimal Mediterranean diet) while older children (age group of 15-18 years) had the lowest ( $18.8 \%)$.

Associations between the consumption of different nutrients included in the Mediterranean diet index and wheezing,

Table 2 Weekly consumption of fruit and vegetables rich in antioxidants

\begin{tabular}{|c|c|c|c|c|c|c|}
\hline & \multicolumn{5}{|c|}{ Consumption per week } & \multirow[b]{2}{*}{ Total } \\
\hline & Never & $<1$ & $1-2$ & $3-4$ & $\geqslant 1 /$ day & \\
\hline Oranges & $21(3.1)$ & 84 (12.3) & $144(21.1)$ & $150(22.0)$ & $282(41.4)$ & 681 \\
\hline Kiwi fruits & $325(48.8)$ & $157(23.6)$ & $72(10.8)$ & $43(6.5)$ & 69 (10.4) & 666 \\
\hline Grapes & $38(5.5)$ & 79 (11.5) & $89(13.0)$ & $156(22.7)$ & $324(47.2)$ & 686 \\
\hline Apples & $12(1.7)$ & $67(9.7)$ & 126 (18.3) & $140(20.3)$ & $343(49.9)$ & 688 \\
\hline Fresh tomatoes & $47(6.9)$ & $40(5.9)$ & 78 (11.4) & $174(25.5)$ & $343(50.3)$ & 682 \\
\hline Green peppers & $349(51.4)$ & 122 (18.0) & 97 (14.3) & $49(7.2)$ & $62(9.1)$ & 679 \\
\hline Carrots & $129(18.8)$ & $309(44.9)$ & $140(20.3)$ & 79 (11.5) & $31(4.5)$ & 688 \\
\hline Broccoli & 462 (68.2) & $134(19.8)$ & $59(8.7)$ & $14(2.1)$ & $8(1.2)$ & 677 \\
\hline
\end{tabular}

Values are given as number (\%). The total represents the number of subjects with available information on the specific food item. 
Table 3 Association between frequency of consumption of fruits and vegetables rich in antioxidants, wheezing and atopy

\begin{tabular}{|c|c|c|c|c|c|c|c|c|c|}
\hline & \multicolumn{3}{|c|}{ Wheezing ever $(n=116)$} & \multicolumn{3}{|c|}{ Wheezing ever with atopy $(n=37)$} & \multicolumn{3}{|c|}{ Atopy never wheezing ( $n=115$ ) } \\
\hline & \multicolumn{2}{|l|}{ Consumption per day } & \multirow[b]{2}{*}{$p$ for trend } & \multicolumn{2}{|l|}{ Consumption per day } & \multirow[b]{2}{*}{$p$ for trend } & \multicolumn{2}{|l|}{ Consumption per day } & \multirow[b]{2}{*}{$p$ for trend } \\
\hline & $<1 /$ day & $\geqslant 1 /$ day & & $<1 /$ day & $\geqslant 1 /$ day & & $<1 /$ day & $\geqslant 1 /$ day & \\
\hline Oranges & $0.28(0.10$ to 0.76$)$ & $0.30(0.11$ to 0.90$)$ & 0.804 & 0.40 (0.08 to 2.02$)$ & $0.33(0.06$ to 1.73$)$ & 0.420 & 0.77 (0.39 to 1.43$)$ & $0.79(0.32$ to 1.87$)$ & 0.473 \\
\hline Kiwi fruits & $0.62(0.39$ to 0.96$)$ & $0.54(0.24$ to 1.19$)$ & 0.039 & 0.60 (0.27 to 1.32$)$ & $0.54(0.15$ to 1.97$)$ & 0.357 & $0.97(0.48$ to 1.95$)$ & $0.79(0.50$ to 1.24$)$ & 0.581 \\
\hline Grapes & $0.26(0.12$ to 0.55$)$ & $0.19(0.09$ to 0.42$)$ & 0.001 & $0.93(0.28$ to 2.21$)$ & 0.88 (0.18 to 4.37$)$ & 0.876 & $0.94(0.38$ to 2.31$)$ & 0.84 (0.34 to 2.07$)$ & 0.852 \\
\hline Apples & $0.14(0.04$ to 0.47$)$ & $0.14(0.04$ to 0.48$)$ & 0.225 & - & - & - & $1.48(0.18$ to 12.10$)$ & $0.85(0.10$ to 7.11$)$ & 0.715 \\
\hline Fresh tomatoes & 0.40 (0.19 to 0.83$)$ & $0.32(0.15$ to 0.67$)$ & 0.010 & 0.55 (0.18 to 1.68$)$ & $0.42(0.14$ to 1.37$)$ & 0.339 & $1.01(0.43$ to 2.35$)$ & $0.93(0.40$ to 2.15$)$ & 0.925 \\
\hline Green peppers & $0.86(0.54$ to 1.36$)$ & $0.54(0.22$ to 1.31$)$ & 0.368 & 0.85 (0.24 to 3.24$)$ & $0.76(0.35$ to 1.64$)$ & 0.784 & $0.91(0.44$ to 1.90$)$ & 0.73 (0.46 to 1.14 ) & 0.379 \\
\hline Carrots & 0.90 (0.52 to 1.57$)$ & 0.75 (0.27 to 2.65$)$ & 0.823 & 1.28 (0.47 to 3.49$)$ & $0.76(0.08$ to 7.41$)$ & 0.810 & 0.96 (0.37 to 2.47$)$ & $0.73(0.08$ to 6.68$)$ & 0.962 \\
\hline Broccoli & $0.93(0.56$ to 1.54$)$ & - & 0.862 & $0.77(0.32$ to 1.85$)$ & - & 0.746 & $0.84(0.32$ to 2.20$)$ & - & 0.935 \\
\hline
\end{tabular}

ORs with $95 \% \mathrm{Cl}$ derived from logistic regression models after adjusting for age, sex, body mass index, parental asthma and number of older siblings.

The reference group for each food item includes those subjects not consuming the specific item.

allergic rhinitis and atopy are shown in table 6. Fruit, vegetable, cereal, and brown bread intakes showed a trend towards negative associations with the outcome variables, although these were not statistically significant. Consumption of nuts more than three times per week was inversely associated with wheezing ever (OR 0.54; 95\% CI 0.34 to $0.86, \mathrm{p}<0.01$ ) and current wheeze (OR $0.46 ; 95 \%$ CI 0.20 to $0.98, \mathrm{p}<0.05$ ). On the other hand, weekly intake of margarine appeared to be harmful to current wheezing (OR 2.19; 95\% CI 1.01 to $4.82, \mathrm{p}<0.05$ ), allergic rhinitis ever (OR 1.99; 95\% CI 1.32 to $3.00, p=0.001$ ) and current allergic rhinitis symptoms (OR 2.10; 95\% CI 1.31 to 3.37, $\mathrm{p}<0.01)$.

Multivariate logistic regression analysis suggested that a high level of adherence to the Mediterranean diet was inversely related to the occurrence of allergic rhinitis ever (OR 0.34; 95\% CI 0.18 to $0.64, \mathrm{p}<0.01$ ), allergic rhinitis ever with atopy (OR $0.39 ; 95 \%$ CI 0.13 to $0.97, \mathrm{p}<0.05$ ), current allergic rhinitis (OR $0.49 ; 95 \%$ CI 0.24 to $0.99, \mathrm{p}<0.05$ ) and nocturnal dry cough apart from a cold in the last 12 months (OR 0.49; $95 \%$ CI 0.23 to $0.96, \mathrm{p}<0.05)$. A high level of adherence to the Mediterranean diet was also protective for wheezing symptoms and atopy, although the associations were not statistically significant (table 7).

Results obtained using the KIDMED score were similar to those using an alternative index (Mediterranean diet score) that evaluated adherence to the Mediterranean diet in adults. ${ }^{18}$ Specifically, the high level of adherence to the Mediterranean diet according to this scale had an inverse association with nocturnal dry cough, apart from a cold in the last 12 months (OR $0.40 ; 95 \%$ CI 0.18 to $0.91, \mathrm{p}<0.05$ ), allergic rhinitis ever (OR $0.45 ; 95 \%$ CI 0.23 to $0.86, \mathrm{p}<0.05$ ) and current allergic rhinitis (OR 0.43; 95\% CI 0.20 to $0.92, \mathrm{p}<0.05$ ) (data not shown).

\section{DISCUSSION}

Children in Crete consume high quantities of locally produced fruits and vegetables; regular and frequent consumption may have a beneficial role against wheezing and rhinitis symptoms. A high consumption of nuts also had a protective effect, while margarine intake was positively associated with reported symptoms. Most of the children had a moderate to high level of adherence to the dietary pattern of the Mediterranean diet. A high level of adherence to the Mediterranean diet showed a protective effect on allergic rhinitis, asthma-like symptoms and atopy, although it was not statistically significant for the last two outcomes. These findings are consistent with results from previous epidemiological studies on the protective effects of citrus fruits, apples and tomatoes on asthma and rhinitis symptoms. ${ }^{5-9}$

A protective effect of grapes has not previously been reported. These were the only fruits to show a consistent inverse association with wheezing ever, current wheezing, allergic rhinitis ever, current allergic rhinitis and current seasonal allergic rhinitis after adjustment for potential confounders. Red grape skin extract contains a mix of non-bioflavonoid polyphenols (derivatives of cinnamic and benzoic acid) and bioflavonoid polyphenols (quercetin, catechins, flavonols, and proanthocyanidins). Oligomeric proanthocyanidins are antioxidants with an anti-inflammatory action that is relevant to oxygen-free radical scavenging, antilipid peroxidation and inhibition of the formation of inflammatory cytokines. ${ }^{20}$ Moreover, resveratrol $\left(3,4^{\prime}, 5\right.$-trihydroxystilbene), a polyphenolic stilbene found in the skins of grapes, has the ability to inhibit cytokine-stimulated inducible nitric oxide synthase expression and nitrite production in human primary airway epithelial cells. ${ }^{21}$ It is possible that the beneficial effect of grape intake on wheezing and allergic rhinitis symptoms is mediated through the antioxidant effect of grape phenolic content.

Table 4 Association between frequency of consumption of fruits and vegetables rich in antioxidants and allergic rhinitis (AR)

\begin{tabular}{|c|c|c|c|c|c|c|c|c|c|}
\hline & \multicolumn{3}{|l|}{ AR ever $(n=129)$} & \multicolumn{3}{|l|}{ Current AR ( $n=92$ ) } & \multicolumn{3}{|c|}{ Current seasonal (AR $n=35$ ) } \\
\hline & \multicolumn{2}{|l|}{ Consumption per day } & \multirow[b]{2}{*}{$p$ for trend } & \multicolumn{2}{|l|}{ Consumption per day } & \multirow[b]{2}{*}{$p$ for trend } & \multicolumn{2}{|l|}{ Consumption per day } & \multirow[b]{2}{*}{$p$ for trend } \\
\hline & $<1 /$ day & $\geqslant 1 /$ day & & $<1 /$ day & $\geqslant 1 /$ day & & $<1 /$ day & $\geqslant 1 /$ day & \\
\hline Oranges & 0.38 (0.14 to 1.01$)$ & $0.29(0.11$ to 0.80$)$ & 0.047 & 0.52 (0.16 to 1.68$)$ & 0.46 (0.15 to 1.48$)$ & 0.419 & $0.97(0.13$ to 8.89$)$ & 0.90 (0.11 to 7.38$)$ & 0.905 \\
\hline Kiwi fruits & 0.75 (0.49 to 1.16$)$ & $0.37(0.16$ to 0.86$)$ & 0.018 & 0.71 (0.43 to 1.16$)$ & $0.47(0.19$ to 1.17$)$ & 0.161 & $0.55(0.26$ to 1.17$)$ & 0.19 (0.03 to 1.48$)$ & 0.113 \\
\hline Grapes & 0.39 (0.19 to 0.82$)$ & $0.31(0.14$ to 0.64$)$ & 0.021 & $0.42(0.19$ to 0.95$)$ & $0.36(0.16$ to 0.81$)$ & 0.046 & $0.28(0.10$ to 0.80$)$ & $0.18(0.06$ to 0.54$)$ & 0.285 \\
\hline Apples & 0.76 (0.19 to 2.98$)$ & $0.46(0.12$ to 1.84$)$ & 0.147 & $0.74(0.15$ to 3.57$)$ & $0.63(0.13$ to 3.06$)$ & 0.712 & 0.62 (0.07 to 5.38 ) & $0.57(0.07$ to 4.95$)$ & 0.870 \\
\hline Fresh tomatoes & 1.37 (0.61 to 3.13 ) & $0.83(0.35$ to 1.94$)$ & 0.224 & $1.36(0.50$ to 3.74$)$ & $1.07(0.40$ to 2.97$)$ & 0.588 & $1.59(0.34$ to 7.35$)$ & $1.07(0.23$ to 5.09$)$ & 0.538 \\
\hline Green peppers & $0.82(0.40$ to 1.68$)$ & $0.75(0.48$ to 1.17$)$ & 0.445 & 1.16 (0.54 to 2.48$)$ & $0.78(0.47$ to 1.29$)$ & 0.489 & $0.60(0.20$ to 1.78$)$ & $0.59(0.20$ to 1.74$)$ & 0.601 \\
\hline Carrots & $0.67(0.28$ to 1.61$)$ & $0.52(0.19$ to 1.39$)$ & 0.403 & 1.15 (0.37 to 3.53$)$ & $0.76(0.22$ to 2.67$)$ & 0.480 & $0.74(0.13$ to 4.09$)$ & $0.86(0.18$ to 4.06$)$ & 0.925 \\
\hline Broccoli & $0.85(0.53$ to 1.36$)$ & - & 0.784 & $0.89(0.52$ to 1.55$)$ & - & 0.920 & $0.96(0.43$ to 2.28$)$ & - & 0.978 \\
\hline
\end{tabular}

ORs with $95 \% \mathrm{Cl}$ derived from logistic regression models after adjusting for age, sex, body mass index, parental asthma and number of older siblings.

The reference group for each food item includes those subjects not consuming the specific item. 
Table 5 Mediterranean diet quality index among children in Crete $(\mathrm{n}=690)$

\begin{tabular}{ll}
\hline Mediterranean diet components & Children, $\mathbf{n}(\%)$ \\
\hline One fruit or fruit juice daily +1 & $645(93.5 \%)$ \\
Two or more fruits daily +1 & $556(80.6 \%)$ \\
One vegetable daily +1 & $622(90.1 \%)$ \\
Two or more vegetables daily +1 & $472(68.4 \%)$ \\
Fish $\geqslant 2$ times per week +1 & $258(37.4 \%)$ \\
Cereals for breakfast daily +1 & $112(16.2 \%)$ \\
Brown bread daily +1 & $120(17.4 \%)$ \\
One dairy product daily +1 & $510(73.9 \%)$ \\
Two or more dairy products daily +1 & $194(28.1 \%)$ \\
Nuts $(\geqslant 3$ times per week) +1 & $312(45.2 \%)$ \\
Red meat $>$ white meat consumption per week -1 & $483(70.0 \%)$ \\
Margarine $>$ once per week -1 & $331(48.0 \%)$ \\
Mediterranean diet score* & \\
Poor ( $\leqslant 3)$ & $150(27.9 \%)$ \\
Average (4-5) & $235(43.8 \%)$ \\
Good (6-10) & $152(28.3 \%)$ \\
Total & 537 \\
\hline
\end{tabular}

*Diet score evaluated for subjects without missing values in specific components.

The study also showed a protective effect of nut consumption on the prevalence of wheezing symptoms. Nuts are a very rich source of vitamin E, the body's principal defence against oxidant-induced membrane injury in human tissue via its role in breaking the lipid peroxidation chain reaction. ${ }^{3}$ The reported results are consistent with those from NHANES study which showed a lower incidence of asthma among women who had a high vitamin $\mathrm{E}$ intake, but the effect in that population was attenuated after excluding nut consumption..$^{22}$ Nuts also have a high magnesium content which has been shown to have a protective effect on asthma symptoms and lung function volumes. ${ }^{12} 23$

Weekly intake of margarine had a harmful effect on asthma and rhinitis symptoms in this population. Margarine is a rich source of omega- 6 polyunsaturated fatty acids such as linoleic acid. Prostaglandins such as prostaglandin E2 are formed by the action of cyclo-oxygenase on arachidonic acid. Arachidonic acid, in turn, is formed from linoleic acid. As a result, an increase in linoleic acid in the diet will promote the formation of prostaglandins with a consequent increase in the likelihood of atopic sensitisation, asthma and atopic disease. ${ }^{24}$ Epidemiological studies in Italy, Germany and Finland have reported a higher consumption of margarine among children with asthma, atopy and allergic rhinitis. ${ }^{825} 26$

We showed a general protective effect of a high level of adherence to the Mediterranean diet on allergic rhinitis, asthma and atopy. Although considerable advances in knowledge have been gained with studies focused on single nutrients or foods, these may fail to account for correlations and interactions between nutrients, and they do not evaluate patterns of dietary intake. ${ }^{27}$ Thus, interest has shifted to the study of food groups and, more recently, dietary patterns including the evaluation of the potential protective role of the Mediterranean diet.

During the past decades a large body of evidence has related adherence to a Mediterranean diet with reductions in all-cause mortality, the prevalence of metabolic disorders such as obesity and high blood pressure, and the incidence of coronary heart disease and various types of cancer. ${ }^{18}{ }^{28-31}$ The ATTICA study suggested that a greater adherence to the Mediterranean diet is associated with increased total antioxidant capacity in healthy adults. ${ }^{14}$ Analyses of the dietary pattern of the traditional diet of Crete have shown a number of protective substances such as selenium, glutathione, resveratrol, a balanced ratio of (n-6):(n3) essential fatty acids, high amounts of fibre, polyphenols from olive oil, vitamins E and C. ${ }^{32}$ The majority of these have marked antioxidant activity. In the present study we showed that a high level adherence to the Mediterranean diet had a protective effect on allergic rhinitis and nocturnal dry cough in the last 12 months. There was a trend for negative associations with wheezing symptoms that did not reach statistical significance, possibly due to the relatively small sample size.

Several indices are available which evaluate adherence to the Mediterranean diet in epidemiological studies. ${ }^{33}$ The KIDMED index is the only Mediterranean diet quality index constructed to evaluate food habits in a population of children and is based on positive and negative component scoring for protective and detrimental nutrients, respectively. ${ }^{17}$ This index was slightly modified to adapt it to the questionnaire and the dietary habits of the studied population. A limitation of the present index is the absence of information on the consumption of "fast foods", sweets and legumes, as these components were not included in the food frequency questionnaire. A higher consumption of red meat than white meat was assigned a negative value as, in the Cretan Mediterranean diet, there is a recommendation for low consumption of red meat (pork, lamb, beef) and its replacement by poultry. ${ }^{34}$ Olive oil serves as the principal source of fat in all Cretan families. ${ }^{35}$ This was also found in this study population and, for that reason, we did not include in the index a question on the use of olive oil at home.

The use of an alternative index of adherence to the Mediterranean diet gave similar results to the KIDMED score. Nonetheless, it remains uncertain how far the observed associations would be modified if other potentially detrimental compounds such as fast foods and sweets were included. Western-type fast food is rarely consumed in rural Crete, and it is likely that the impact of such foods on the diet of school children was minor.

We are aware of some inherent limitations to our survey. First, its cross-sectional methodology is not optimal for the assessment of causal relationships and can only be suggestive of an association between dietary intake and respiratory

Table 6 Associations between nutrients included in the Mediterranean diet index and wheezing, allergic rhinitis and atopy

\begin{tabular}{llllll}
\hline & Wheezing ever & Current wheezing & Allergic rhinitis ever & Current allergic rhinitis & Atopy \\
\hline One fruit or fruit juice daily & $0.61(0.27$ to 1.39$)$ & $0.63(0.23$ to 1.42$)$ & $0.77(0.34$ to 1.78$)$ & $0.78(0.36$ to 1.81$)$ & $0.72(0.33$ to 1.57$)$ \\
One vegetable daily & $0.65(0.37$ to 1.79$)$ & $0.85(0.37$ to 1.93$)$ & $0.80(0.51$ to 1.75$)$ & $0.85(0.49$ to 1.86$)$ & $0.92(0.60$ to 1.42$)$ \\
Fish $\geqslant 2$ times per week & $0.67(0.42$ to 1.07$)$ & $0.69(0.31$ to 1.56$)$ & $0.88(0.58$ to 1.34$)$ & $0.90(0.56$ to 1.72$)$ & $0.70(0.47$ to 1.03$)$ \\
Cereals for breakfast daily & $0.64(0.24$ to 1.71$)$ & $0.79(0.26$ to 1.84$)$ & $0.71(0.32$ to 1.57$)$ & $0.93(0.45$ to 1.93$)$ & $0.81(0.35$ to 1.90$)$ \\
Brown bread daily & $0.79(0.42$ to 1.50$)$ & $0.51(0.14$ to 1.72$)$ & $0.95(0.53$ to 1.70$)$ & $0.89(0.45$ to 1.75$)$ & $1.04(0.63$ to 1.71$)$ \\
One dairy product daily & $1.09(0.63$ to 1.90$)$ & $1.14(0.64$ to 2.10$)$ & $1.03(0.62$ to 1.70$)$ & $1.14(0.62$ to 2.05$)$ & $0.77(0.49$ to 1.22$)$ \\
Nuts $\geqslant 3$ times per week & $0.54(0.34$ to 0.86$)$ & $0.46(0.20$ to 0.98$)$ & $0.77(0.51$ to 1.18$)$ & $0.83(0.57$ to 1.46$)$ & $0.76(0.52$ to 1.20$)$ \\
Red meat $>$ white meat consumption & $1.05(0.62$ to 1.78$)$ & $1.53(0.66$ to 3.54$)$ & $1.04(0.64$ to 1.69$)$ & $1.13(0.65$ to 1.98$)$ & $1.06(0.67$ to 1.68$)$ \\
$\quad$ per week & & & & & \\
Margarine $>$ once per week & $1.47(0.95$ to 2.26$)$ & $2.19(1.01$ to 4.82$)$ & $1.99(1.32$ to 3.00$)$ & $2.10(1.31$ to 3.37$)$ & $1.08(0.73$ to 1.59$)$ \\
\hline
\end{tabular}

ORs with $95 \% \mathrm{Cl}$ derived from logistic regression models after adjusting for age, sex, body mass index, parental asthma and number of older siblings. 
Table 7 Association between the level of adherence to the Mediterranean diet and wheezing, allergic rhinitis and atopy

\begin{tabular}{llll}
\hline & Average diet score $(\mathbf{n = 2 3 5 )}$ & High diet score $(\mathbf{n}=152)$ & $\mathrm{p}$ for trend \\
\hline Wheezing ever & $0.94(0.64$ to 2.02$)$ & $0.67(0.34$ to 1.32$)$ & 0.229 \\
Wheezing ever with atopy & $0.98(0.45$ to 2.79$)$ & $0.53(0.16$ to 1.80$)$ & 0.417 \\
Current wheezing & $0.92(0.41$ to 2.83$)$ & $0.64(0.20$ to 2.05$)$ & 0.564 \\
Nocturnal cough (last 12 months) & $0.68(0.36$ to 1.27$)$ & $0.49(0.23$ to 0.96$)$ & 0.095 \\
Allergic rhinitis ever & $0.70(0.42$ to 1.16$)$ & $0.34(0.18$ to 0.64$)$ & 0.004 \\
Allergic rhinitis ever with atopy & $1.14(0.50$ to 2.57$)$ & $0.39(0.13$ to 0.97$)$ & 0.102 \\
Current allergic rhinitis & $0.77(0.43$ to 1.39$)$ & $0.49(0.24$ to 0.99$)$ & 0.142 \\
Current seasonal allergic rhinitis & $0.63(0.24$ to 1.65$)$ & $0.51(0.20$ to 1.25$)$ & 0.321 \\
Atopy & $0.94(0.51$ to 1.72$)$ & $0.54(0.21$ to 1.99$)$ & 0.384 \\
\hline
\end{tabular}

symptoms. Second, the high frequency of "ever wheeze" may reflect different aetiological types of disease such as transient wheezing, non-atopic wheezing and IgE-associated wheezing. ${ }^{36}{ }^{37}$ Triansient wheezing usually resolves after the age of 3 years, ${ }^{38}$ so there may have been difficulties in recalling this symptom at the time the study was performed. To disentangle children with the atopic phenotype, we examined separately children who reported the symptom (ever wheeze), children who had the combination of the symptom with a positive allergy test, and children who were atopic without experiencing the symptom. $32 \%$ of the children who reported the symptom also had a positive skin prick test. The rest of the cases may correspond to non-atopic wheezers who may experience symptoms of bronchoconstriction independently of atopic sensitisation. Non-atopic wheezing has been associated with viral infections in infancy and a lower level of pulmonary function. ${ }^{39}$ When we stratified analyses by age group (712 years and $>12$ years) the results were similar in both groups, although statistically significant for many of the foods only in the younger age group, possibly due to the small sample size. We had no information on parental atopy to determine whether this discrepancy in the prevalence of atopy/wheezing also holds for the parents or whether this community has a particular genetic background. Although the present study refers to cross-sectional data, the demonstration of negative associations between dietary intake of fruits, vegetables, nuts and wheezing/rhinitis symptoms are consistent with the hypothesis that a dietary pattern rich in antioxidants may have a protective effect on the inflammatory response from early childhood to adolescence. To evaluate further the role of such exposures in childhood allergic disease, longitudinal studies with measurement of lung function volumes, bronchial hyper-responsiveness and parental atopy are needed.

A weakness of this study is the self-administered nature of the questionnaire. This was based on the ISAAC questionnaire and we followed a formal procedure of forward/backward translation to establish the corresponding Greek questions. Although we cannot exclude linguistic and cultural influences in the report of wheezing, such influences would mainly affect international comparisons rather than comparisons within a culturally homogeneous population.

Although the cross-sectional design of the present study did not permit the collection of information on change of diet over time, we think it is very unlikely that children in Crete change their diet due to their respiratory symptoms. The food frequency questionnaire that we developed has not been validated in this population; however, it seems improbable that any subsequent misclassification of dietary intake would be other than random. Studies of nutrition in childhood suggest that food frequency methods produce both valid and reproducible estimates of the dietary intakes of children and adolescents. ${ }^{40}$
Some analyses, such as those examining the consumption of oranges and apples, were based on a reference group that included few subjects. A sensitivity analysis using alternative groups of exposure gave essentially the same results, indicating that the protective effect of consumption of fruits and vegetables was not dependent on arbitrary categorisations.

Our findings indicate that a high dietary intake of commonly consumed fruits and vegetables and nuts may have a protective role on the prevalence of asthma-like symptoms and allergic rhinitis. A high level of adherence to the Mediterranean diet had a beneficial effect on allergic rhinitis, asthma-like symptoms and atopy, although this was not statistically significant for the last two outcomes. A diet high in antioxidants may prevent the expression of allergic disease in this population.

\section{Authors' affiliations \\ Leda Chatzi, Gianna Apostolaki, Nikolaos Tzanakis, Manolis Kogevinas, Department of Social Medicine, Faculty of Medicine, University of Crete, Heraklion, Greece \\ loannis Bibakis, Vasilki Bibaki-Liakou, Anti-Tuberculosis Unit, Venezelio General Hospital, Heraklion, Crete, Greece \\ Isabel Skypala, Paul Cullinan, Royal Brompton Hospital and National Heart and Lung Institute, London, UK \\ Manolis Kogevinas, Centre for Research in Environmental Epidemiology, IMIM, Barcelona, Spain}

Financial support for this study was provided by Medicor and through the Fifth Framework of the European Community (QLK4-CT-2000-00263).

Competing interests: None.

\section{REFERENCES}

1 Devereux G, Seaton A. Diet as a risk factor for atopy and asthma. J Allergy Clin Immunol 2005;115:1109-17.

2 McKeever TM, Britton J. Diet and asthma. Am J Respir Crit Care Med 2004;170:725-9.

3 Romieu I, Trenga C. Diet and obstructive lung diseases. Epidemiol Rev 2001;23:268-87.

4 Patel BD, Welch AA, Bingham SA, et al. Dietary antioxidants and asthma in adults. Thorax 2006;61:388-93.

5 Shaheen SO, Sterne JA, Thompson RL, et al. Dietary antioxidants and asthma in adults: population-based case-control study. Am J Respir Crit Care Med 2001;164:1823-8.

6 Romieu I, Varraso R, Avenel V, et al. Fruit and vegetable intakes and asthma in the E3N study. Thorax 2006;61:209-15.

7 Garcia V, Arts IC, Sterne JA, et al. Dietary intake of flavonoids and asthma in adults. Eur Respir J 2005;26:449-52.

8 Farchi S, Forastiere F, Agabiti N, et al. Dietary factors associated with wheezing and allergic rhinitis in children. Eur Respir J 2003;22:772-80.

9 Forastiere F, Pistelli R, Sestini P, et al. Consumption of fresh fruit rich in vitamin $C$ and wheezing symptoms in children. SIDRIA Collaborative Group, Italy (Italian Studies on Respiratory Disorders in Children and the Environment). Thorax 2000;55:283-8

10 Cook DG, Carey IM, Whincup PH, et al. Effect of fresh fruit consumption on lung function and wheeze in children. Thorax 1997;52:628-33. 
11 Antova T, Pattenden S, Nikiforov B, et al. Nutrition and respiratory health in children in six Central and Eastern European countries. Thorax 2003;58:231-6.

12 Hijazi N, Abalkhail B, Seaton A. Diet and childhood asthma in a society in transition: a study in urban and rural Saudi Arabia. Thorax 2000;55:775-9

13 Fito M, Cladellas M, de la Torre R, et al. Antioxidant effect of virgin olive oil in patients with stable coronary heart disease: a randomized, crossover, controlled, clinical trial. Atherosclerosis 2005;181:149-58.

14 Pitsavos C, Panagiotakos DB, Tzima N, et al. Adherence to the Mediterranean diet is associated with total antioxidant capacity in healthy adults: the ATTICA study. Am J Clin Nutr 2005;82:694-9.

15 Zekveld C, Bibakis I, Bibaki-Liakou V, et al. The effects of farming and birth order on asthma and allergies. Eur Respir J 2006;28:82-8.

16 Serra-Majem L, Ribas L, Garcia A, et al. Nutrient adequacy and Mediterranean diet in Spanish school children and adolescents. Eur J Clin Nutr 2003;57(Suppl 1):S35-9.

17 Serra-Majem L, Ribas L, Ngo J, et al. Food, youth and the Mediterranean diet in Spain. Development of KIDMED, Mediterranean Diet Quality Index in children and adolescents. Public Health Nutr 2004;7:931-5.

18 Trichopoulou A, Costacou T, Bamia C, et al. Adherence to a Mediterranean diet and survival in a Greek population. N Engl J Med 2003;348:2599-608.

19 Cole TJ, Bellizzi MC, Flegal KM, et al. Establishing a standard definition for child overweight and obesity worldwide: international survey. BMJ 2000;320:1240-3.

20 Li WG, Zhang XY, Wu YJ, et al. Anti-inflammatory effect and mechanism of proanthocyanidins from grape seeds. Acta Pharmacol Sin 2001;22:1117-20.

21 Donnelly LE, Newton R, Kennedy GE, et al. Anti-inflammatory effects of resveratrol in lung epithelial cells: molecular mechanisms. Am J Physiol Lung Cell Mol Physiol 2004;287:L774-83.

22 Troisi RJ, Willett WC, Weiss ST, et al. A prospective study of diet and adult-onset asthma. Am J Respir Crit Care Med 1995;151:1401-8.

23 Britton J, Pavord I, Richards K, et al. Dietary magnesium, lung function, wheezing, and airway hyperreactivity in a random adult population sample. Lancet 1994;344:357-62.

24 Black PN, Sharpe S. Dietary fat and asthma: is there a connection? Eur Respir J 1997; 10:6-12.

25 Bolte G, Frye C, Hoelscher B, et al. Margarine consumption and allergy in children. Am J Respir Crit Care Med 2001;163:277-9.

26 Dunder T, Kuikka L, Turtinen J, et al. Diet, serum fatty acids, and atopic diseases in childhood. Allergy 2001;56:425-8.
27 Jacobs DR Jr, Steffen LM. Nutrients, foods, and dietary patterns as exposures in research: a framework for food synergy. Am J Clin Nutr 2003;78/3 Suppl):508-13S.

28 Knoops KT, de Groot LC, Kromhout D, et al. Mediterranean diet, lifestyle factors, and 10-year mortality in elderly European men and women: the HALE project. JAMA 2004;292:1433-9.

29 Panagiotakos DB, Chrysohoou C, Pitsavos C, et al. The association of Mediterranean diet with lower risk of acute coronary syndromes in hypertensive subjects. Int J Cardiol 2002;82:141-7.

30 Trichopoulou A, Lagiou P, Kuper H, et al. Cancer and Mediterranean dietary traditions. Cancer Epidemiol Biomarkers Prev 2000;9:869-73.

31 Martinez-Gonzalez MA, Fernandez-Jarne E, Serrano-Martinez M, et al. Mediterranean diet and reduction in the risk of a first acute myocardial infarction an operational healthy dietary score. Eur J Nutr 2002;41:153-60.

32 Simopoulos AP. The Mediterranean diets: what is so special about the diet of Greece? The scientific evidence. J Nutr 2001;131(11 Suppl):3065-73S.

33 Bach A, Serra-Majem L, Carrasco JL, et al. The use of indexes evaluating the adherence to the Mediterranean diet in epidemiological studies: a review. Public Health Nutr 2006;9:132-46.

34 Renaud S, de Lorgeril M, Delaye J, et al. Cretan Mediterranean diet for prevention of coronary heart disease. Am J Clin Nutr 1995;61/6 Suppl):1360-7S.

35 Hassapidou M, Kafatos A, Manoukas G. Dietary vitamin E intake and plasma tocopherol levels of a group of adolescents from Spili, Crete. Int J Food Sci Nutr 1996;47:365-8.

36 Martinez FD. Development of wheezing disorders and asthma in preschool children. Pediatrics 2002;109(2 Suppl):3627.

37 Martinez FD, Wright AL, Taussig LM, et al. Asthma and wheezing in the first six years of life. The Group Health Medical Associates. N Engl J Med 1995;332:133-8.

38 Stein RT, Holberg CJ, Morgan WJ, et al. Peak flow variability, methacholine responsiveness and atopy as markers for detecting different wheezing phenotypes in childhood. Thorax 1997;52:946-52.

39 Stein RT, Sherrill D, Morgan WJ, et al. Respiratory syncytial virus in early life and risk of wheeze and allergy by age 13 years. Lancet 1999;354:541-5.

40 Rockett H, Wolf A, Colditz G, Development and reproducibility of food frequency questionnaire to assess diets of older children and adolescents. J Am Diet Assoc 1995;95:336-40.

\section{LUNG ALERT}

\section{Bronchoscopy in haematopoietic stem cell transplant recipients may not be beneficial}

A Hofmeister CC, Czerlanis C, Forsythe S, et al. Retrospective utility of bronchoscopy after hematopoietic stem cell transplant. Bone Marrow Transplant 2006;38:693-8.

$\mathrm{H}$ aemopoietic stem cell transplant (HSCT) recipients have a high rate of pulmonary complications, and bronchoscopy is traditionally felt to be beneficial as part of diagnostic examination. This was a retrospective review of HSCT patients in a single institution who had undergone bronchoscopy over a 10-year period; it aimed to assess whether alterations in management based on bronchoscopy results led to a survival advantage.

Of 1651 HSCTs that were performed, two-thirds were autologous; 190 patients were admitted for pneumonia and 101 bronchoscopies were performed, but complete records were only available for 91 episodes in 78 patients. Forty nine per cent of bronchoscopies gave a probable diagnosis, with the commonest organisms isolated being Aspergillus, cytomegalovirus, Gramnegative bacteria and other viruses. All patients were on prophylactic antibacterial, antifungal, antipneumocystis and antiviral treatment.

The overall median survival after bronchoscopy was 35 days with no statistically significant difference in survival between bronchoscopies, which yielded a diagnosis (infective or otherwise) compared with those that did not (29 vs 46 days, $\mathrm{p}=0.165)$, nor between those in which diagnosis led to a change in treatment or not ( 31 vs 24 days, $p=0.546$ ). Complications occurred in seven of 91 bronchoscopies, 6 of which involved bleeding after transbronchial biopsy. The additional yield of transbronchial biopsy over bronchoalveolar lavage was only 5\%, and the authors therefore do not recommend performing transbronchial biopsy. Overall, the benefit of bronchoscopy in HSCT recipients is questioned.

The study was limited by selection bias, relatively small numbers and the retrospective, single centre design. Further, prospective studies in other centres are needed to better characterise the benefit of bronchoscopy in this patient group. 